\title{
Atmospheric Dispersion of Sodium Aerosol due to a Sodium Leak in a Fast Breeder Reactor Complex*
}

\author{
G. PUNITHA**, A. Jasmin SUDHA**, N. KASINATHAN** and M. RAJAN** \\ **Safety Engineering Division, Safety Group, \\ Indira Gandhi Centre for Atomic Research, Kalpakkam - 603102, INDIA \\ E-mails: punitha@igcar.gov.in; jasmin@igcar.gov.in; nkasi@igcar.gov.in; rajanm@igcar.gov.in
}

\begin{abstract}
Liquid sodium at high temperatures $(470 \mathrm{~K}$ to $825 \mathrm{~K})$ is used as the primary and secondary coolant in Liquid Metal cooled Fast Breeder Reactors (LMFBR). In the event of a postulated sodium leak in the Steam Generator Building (SGB) of a LMFBR, sodium readily combusts in the ambient air, especially at temperatures above $523 \mathrm{~K}$. Intense sodium fire results and sodium oxide fumes are released as sodium aerosols. Sodium oxides are readily converted to sodium hydroxide in air due to the presence of moisture in it. Hence, sodium aerosols are invariably in the form of particulate sodium hydroxide. These aerosols damage not only the equipment and instruments due to their corrosive nature but also pose health hazard to humans. Hence, it is essential to estimate the concentration of sodium aerosols within the plant boundary for a sodium leak event. The Gaussian Plume Dispersion Model can obtain the atmospheric dispersion of sodium aerosols in an open terrain. However, this model does not give accurate results for dispersion in spaces close to the point of release and with buildings in between. The velocity field due to the wind is altered to a large extent by the intervening buildings and structures. Therefore, a detailed 3-D estimation of the velocity field and concentration has to be obtained through rigorous computational fluid dynamics (CFD) approach. PHOENICS code has been employed to determine concentration of sodium aerosols at various distances from the point of release. The dispersion studies have been carried out for the release of sodium aerosols at different elevations from the ground and for different wind directions.
\end{abstract}

Key words: Sodium Aerosol, Dispersion, Gaussian Plume Model, CFD

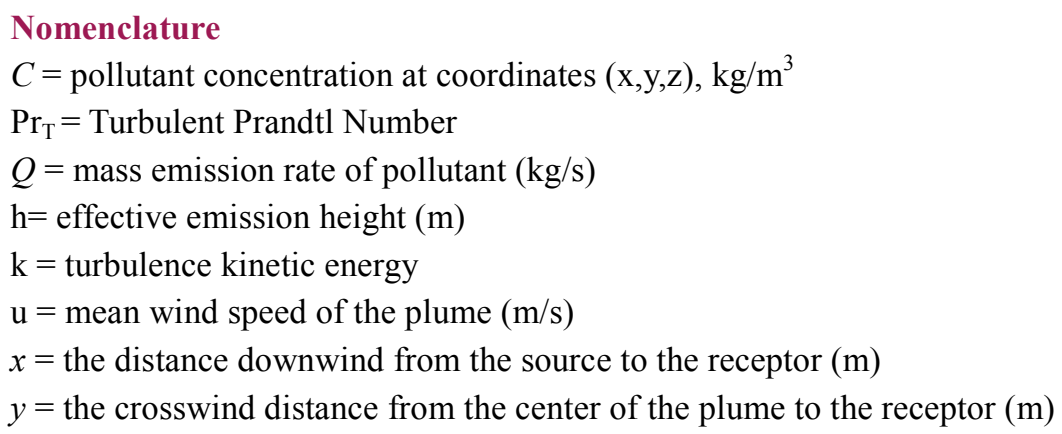


$z=$ the height above ground level of the receptor $(\mathrm{m})$

$\varepsilon=$ dissipation rate of turbulence energy

$\mu_{\mathrm{L}}=$ Laminar viscosity

$\mu_{\mathrm{T}}=$ Turbulent viscosity

$\tau=$ Inverse of rate constant for the first order reaction of sodium hydroxide conversion to sodium carbonate in seconds (considered as $300 \mathrm{~s}$ in these calculations).

$\sigma_{\mathrm{y}}=$ standard deviation of plume concentration in the crosswind direction (m)

$\sigma_{\mathrm{z}}=$ standard deviation of plume concentration in the vertical direction (m)

\section{Introduction}

In the event of a postulated sodium leak in LMFBR, sodium fire results and releases dense sodium aerosols as sodium oxides and hydroxide, which cause material damage due to their corrosive nature. They also pose health hazard to humans when the concentration of exposure exceeds the allowable limits. Effects due to inhalation of sodium hydroxide aerosols may vary from mild irritation of nose to severe pneumonia depending on the severity of the exposure. Available literature supports the fact that concentration of sodium hydroxide aerosols less than $2 \mathrm{mg} / \mathrm{m}^{3}$ does not pose any health problem for repeated exposure for 8 hours a day for 40 years (ACGIH, 1993). Hence, it is essential to estimate the concentration of sodium aerosols inside the plant boundary and at site boundary for sodium leak inside SGB. Generally, atmospheric dispersion studies have been carried out using dedicated codes like SPEEDI (Venkatesan R, 2002) or by CFD methods (Abedi, 2003). In the present study, Gaussian Plume Dispersion model is utilized to estimate the concentration of sodium hydroxide aerosols at the site boundary (1600 m from SGB) and CFD model is used to estimate the same within the plant boundary.

\section{Behavior of Sodium Aerosols in Air}

Sodium melts at $371 \mathrm{~K}$ and boils at $1156 \mathrm{~K}$. When liquid sodium above $523 \mathrm{~K}$ leaks in the atmosphere, it starts burning. In sodium combustion process, sodium comes in contact with air and reacts immediately to form sodium oxides $\mathrm{Na}_{2} \mathrm{O}, \mathrm{Na}_{2} \mathrm{O}_{2}$ and $\mathrm{NaO}_{2}$. These oxides are formed in a solid phase and are heavier than the liquid sodium and generally sink inside the sodium pool. However, a significant portion of the oxides, in the form of fine particles, are entrained out of the surface by the buoyancy induced upward movement of the air. Oxide aerosols react immediately with moisture to form sodium hydroxide. Sodium hydroxide particles react with $\mathrm{CO}_{2}$ in air to form sodium carbonate particles.

The fire may be spray (due to a small continuous leak from the pipeline), pool or a combination of both. Sustained sodium burning inside SGB is possible only due to pool fire mode of sodium combustion. Spray mode of sodium combustion will be rare and its effect will be pronounced only for a short duration in the beginning and hence it is not considered in the present analysis. Rate of release of sodium aerosols from SGB depends on the burning rate of sodium in a pool fire, area of pool fire formed, extent of aerosols formed and extent of aerosols deposited within the SGB.

\section{Conversion of Sodium Hydroxide to Carbonate}

Conversion rate of sodium hydroxide to carbonate is quite slow compared to the rate of conversion of sodium oxide to hydroxide, which is almost instantaneous. The experiments of FAUNA facility indicates $90 \%$ conversion of $\mathrm{NaOH}$ to carbonate in 260 seconds (Cherdron, 1984). 
Aerosol Release due to Sodium Leak in SGB

The sodium aerosol production rate $\mathrm{Q}(\mathrm{kg} / \mathrm{s})$ is the input condition used in this calculation for the estimation of consequences at the site boundary. When the fire is identified, the ventilation fans are switched off automatically. This will lead to the reduction in sodium burning rate and increase in deposition of aerosols inside the building. A constant burning rate is assumed as a conservative approach. However, the advantage due to deposition of aerosols inside the building has been considered.

The basic assumptions used in the computation of boundary conditions for all category of events are:

- Sodium burns as pool fire. (Sustained sodium burning inside SGB is possible only due to pool fire).

- Average sodium pool burning rate is $40 \mathrm{~kg} / \mathrm{m}^{2} / \mathrm{h}$ (Newman, 1983). The burning rate of sodium pool varies from $20-40 \mathrm{~kg} / \mathrm{m}^{2} / \mathrm{h}$. A conservative value has been taken for computation.

- When sodium burns, $30 \%$ of the product mass manifests as aerosols. Several experimental reports support this fact (Yamaguchi, 2003).

- $80 \%$ of these aerosols get deposited on the floor, walls and ducts (IAEA TECDOC-908, 1996).

It is assumed that the sodium will spread on the floor area completely so that the actual area available for pool fire is $100 \%$ of the SGB floor area. The rate of release of aerosols to atmosphere depends on type of fire, burning rate, area of sodium pool formed, aerosol production rate and its settling inside a building. The release of sodium aerosols through SGB vent is estimated to be $0.552 \mathrm{~kg} / \mathrm{s}$. This value is used as the input for further calculations.

\section{Concentration of Sodium Aerosols at Site Boundary}

The Gaussian plume dispersion model shown in Fig. 1 is a simple, steady state, single point source dispersion model, which gives accurate results for plain, uninterrupted terrains from $100 \mathrm{~m}$ to $4000 \mathrm{~m}$ from the point of source of release (Turner, 1969). The Gaussian plume model is widely used to calculate the atmospheric dispersion of airborne materials. Most of the computer codes for radiological airborne releases are based on the Gaussian plume dispersion modeling (V.V.Shirvaikar, 1973). The estimates from this model are generally conservative due to the fact that inhomogenous flow is not modeled. Such a conservative analysis is acceptable from the safety perspective. In the present analysis, it has been used to predict aerosol dispersion at a distance of $1.6 \mathrm{~km}$ away from the source where the validity of the model is quite strong.

Gaussian dispersion model has been derived by assuming that the concentration of chemicals in a plume follows a Gaussian normal distribution in the vertical and horizontal directions perpendicular to wind direction. Dispersion and dilution of a pollutant is directly proportional to the prevailing wind velocity. Since large open coastal spaces in the southern peninsula are subjected to a wind velocity of $1 \mathrm{~m} / \mathrm{s}$ for most of the time, the same is used as the input in the computation. The worst weather condition F (Stable) as defined by the Pasquill chart is considered for calculating the aerosol diffusion. Particle deposition or absorption is neglected in this calculation. The following equation which includes mass distribution in vertical direction $\mathrm{z}$ (considering the effect of surface reflection), mass distribution in crosswind direction and conversion to carbonate particles (considering the reaction is of first order) is used to find the concentration of sodium hydroxide at site boundary. 
$C(x, y, z)=\frac{Q}{2 \pi \sigma_{Y} \sigma_{z} u}\left\{\exp \left(\frac{-(z-h)^{2}}{2 \sigma_{z}^{2}}\right)+\exp \left(\frac{-(z+h)^{2}}{2 \sigma_{z}{ }^{2}}\right)\right\}\left\{\exp \left(\frac{-(y)^{2}}{2 \sigma_{y}{ }^{2}}\right)\right\} \exp \left(\frac{-x}{u \tau}\right)$

where $\sigma_{y}=A_{y} x^{0.9031} ; \quad \sigma_{z}=A_{z} x^{q}+R ; \quad \mathrm{A}_{\mathrm{y}}=0.0722$

\begin{tabular}{|c|c|c|c|}
\hline Distance & $\mathrm{A}_{\mathrm{z}}$ & $\mathrm{q}$ & $\mathrm{R}$ \\
\hline $\mathrm{x}<0.1 \mathrm{~km}$ & 0.053 & 0.814 & 0 \\
\hline $0.1 \mathrm{~km} \leq \mathrm{x} \leq 1.0 \mathrm{~km}$ & 0.086 & 0.74 & -0.35 \\
\hline $\mathrm{x} \geq 1.0 \mathrm{~km}$ & 18.1 & 0.18 & -48.6 \\
\hline
\end{tabular}

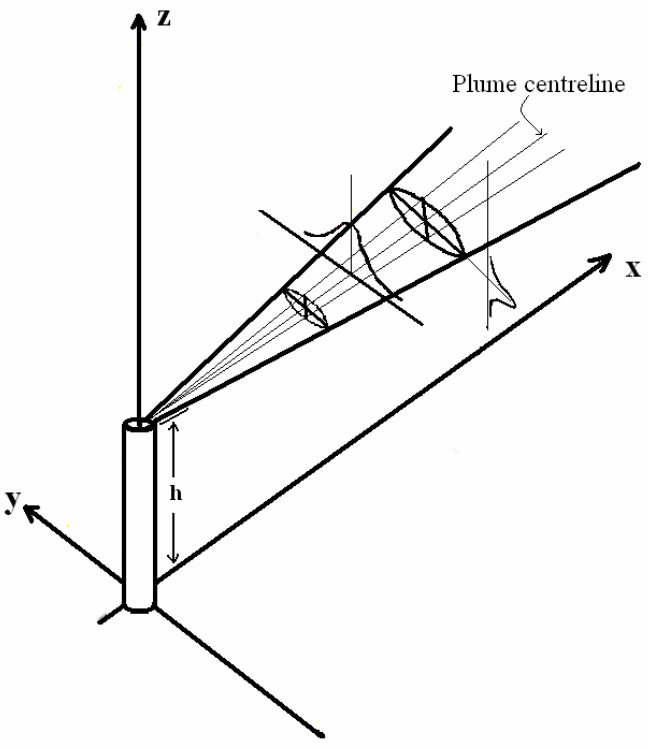

Fig.1 Gaussian Plume Behavior

\section{Results of Gaussian Plume Dispersion}

The dispersion studies have been carried out for the release of sodium aerosols at $5 \mathrm{~m}$, $10 \mathrm{~m}, 20 \mathrm{~m}$ and $30 \mathrm{~m}$ elevations from the ground. The magnitude of free stream wind velocity is considered as $1 \mathrm{~m} / \mathrm{s}$. Concentration of the sodium aerosols is estimated taking into account the conversion to carbonate by first order reaction and the results are shown in Fig.2.

It is seen that the concentration of sodium aerosols at $1600 \mathrm{~m}$ (site boundary) is in the range between $0.8 \times 10^{-3} \mathrm{mg} / \mathrm{m}^{3}$ and $5 \times 10^{-3} \mathrm{mg} / \mathrm{m}^{3}$ which is very much smaller than internationally acceptable limit of $2 \mathrm{mg} / \mathrm{m}^{3}$. 


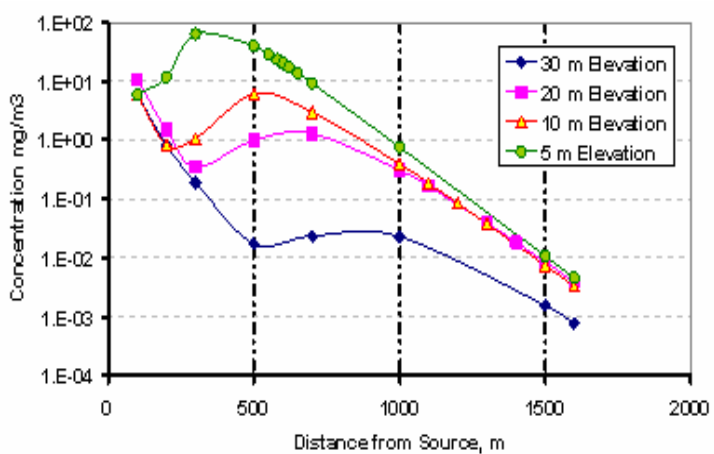

Fig.2 Ground Level Concentration for Various Source Elevations

\section{Dispersion of Sodium Aerosols within Plant Boundary}

The dispersion of sodium aerosols in the atmosphere depends to a large extent on the presence of intervening buildings and structures, especially for distances close to the point of release. Within the plant, the intervening buildings and structures alter the velocity field to a large extent. When an air pollution plume flows over nearby buildings or other structures, turbulent eddies are formed in the downwind side of the building. Those eddies cause a plume from a stack source to be forced down to the ground much sooner than it would if a building or structure were not present. The effect can greatly increase the resulting near-by ground-level pollutant concentrations downstream of the building or structure. Therefore, Gaussian plume dispersion model could not be used in this case. Hence, Computational fluid dynamics (CFD) approach has been used to obtain a detailed 3-D estimation of the velocity field and concentration.

\section{CFD Model}

Computational fluid dynamic models provide analysis of fluid flow by solving simultaneously conservation of mass, momentum and species concentration equations using finite volume methods in three dimensions. In the present problem, the concentration of sodium hydroxide aerosols is also to be determined. Therefore, the transport equation for concentration also has to be solved. The governing equations in their tensor form are listed below.

Continuity Equation

$$
\rho \sum_{i} \frac{\partial u_{i}}{\partial x_{i}}=0
$$

Momentum equation

$$
\begin{aligned}
& \rho \sum_{i}\left(u_{i} \frac{\partial u_{i}}{\partial x_{i}}\right)=\sum_{i} \frac{\partial P}{\partial x_{i}}+\mu \frac{\partial^{2} u_{i}}{\partial x_{i}^{2}} \\
& \mu=\mu_{\mathrm{L}}+\mu_{\mathrm{T}}
\end{aligned}
$$

Where

$$
\begin{aligned}
& \mu_{\mathrm{L}}=\text { Laminar viscosity } \\
& \mu_{\mathrm{T}}=\text { Turbulent viscosity }
\end{aligned}
$$


Conservation of mass of a single pollutant species of concentration $\mathrm{C}$ is given by

$$
\begin{aligned}
& \rho \sum_{i} \frac{\partial\left(u_{i} C\right)}{\partial x_{i}}=\rho \sum_{i} \frac{\partial}{\partial x_{i}}\left(D \frac{\partial C}{\partial x_{i}}\right) \\
& \mathrm{D}=\mathrm{D}_{\mathrm{L}}+\mathrm{D}_{\mathrm{T}}
\end{aligned}
$$

The turbulent diffusivity coefficient is given as

$$
D_{T}=v_{T} \quad\left(\operatorname{Pr}_{\mathrm{T}}=1\right)
$$

To determine the flow field and pollutant concentration within the computational domain, the above mentioned set of partial differential equations has to be solved, together with appropriate boundary conditions. The mathematical model has been derived based on the following assumptions. The flow field is steady state, three dimensional, incompressible, viscous, turbulent and in Cartesian frame. Turbulence is calculated using the standard $\mathrm{k}-\varepsilon$ model to compute the isotropic eddy viscosity parameter present in both the momentum and pollution transport equations, which assumes that a pollutant is diluted equally in all directions. The diffusion is primarily turbulent and hence the laminar diffusivity coefficient $\mathrm{D}_{\mathrm{L}}$ is assumed to be zero. The model is based on the concept that the Reynolds stresses are linearly related to rates of mean strain by means of a 'turbulent viscosity', which acts in an analogous manner to the physical viscosity of the fluid but depends on local flow conditions. In the $\mathrm{k}-\varepsilon$ model, additional conservation equations are solved for turbulence kinetic energy $(\mathrm{k})$, and for the dissipation rate of turbulence energy ( $\varepsilon$ ) (Holmes, 2006). The computed values of $\mathrm{k}$ and $\varepsilon$ are used to construct turbulent length and velocity scales which are in turn used to provide local values for the turbulent viscosity.

The k- $\varepsilon$ model employs the following turbulence transport equations:

$$
\begin{gathered}
\rho \frac{\partial}{\partial x_{i}}\left[u_{i} k-\frac{v_{T}}{\operatorname{Pr}_{T}} \frac{\partial k}{\partial x_{i}}\right]=\rho(P-k) \\
\rho \frac{\partial}{\partial x_{i}}\left[u_{i} \varepsilon-\frac{v_{T}}{\operatorname{Pr}_{T}} \frac{\partial \varepsilon}{\partial x_{i}}\right]=\rho \frac{\varepsilon}{k}\left(C_{1} P-C_{2} \varepsilon\right)
\end{gathered}
$$

The kinematic turbulent (or eddy) viscosity $\mu_{\mathrm{T}}$ is given by:

$$
\frac{\mu_{T}}{\rho}=v_{T}=C_{\mu} C_{d} \frac{k^{2}}{\varepsilon}
$$

Where $\mathrm{C}_{1}=1.44 ; \quad \mathrm{C}_{2}=1.92 ; \quad \mathrm{C}_{\mu}=0.5478 ; \quad \mathrm{C}_{\mathrm{d}}=0.1643$

\section{Results and Discussion}

The formulated mathematical model is implemented in the CFD code PHOENICS which uses finite volume formulation to solve the equations. The buildings are modeled as solid 3D blockages. The dimensions of computational domain are $600 \mathrm{~m}$ x $600 \mathrm{~m} \times 300 \mathrm{~m}$ and the domain is divided into 13, 18 and 7 regions in $\mathrm{x}, \mathrm{y}$ and $\mathrm{z}$ directions respectively. The finest grid size is $1 \mathrm{~m}$ and the coarsest grid size is $10 \mathrm{~m}$. Finest grid is defined around the point of release of aerosol in SGB. The maximum height of building in the domain is $55 \mathrm{~m}$. It is found that dispersion of aerosol is dominant close to the ground level due to the presence of obstructing buildings. Hence more number of grids are provided upto the height of $55 \mathrm{~m}$, the grid size varying between $1 \mathrm{~m}$ to $5 \mathrm{~m}$. Above that elevation one grid is defined for every $10 \mathrm{~m}$ of height. In the $\mathrm{x}-\mathrm{y}$ plane which is ground plane, the cell size is $10 \mathrm{~m} \times 10 \mathrm{~m}$ 
except the regions where the layout of the buildings demanded a finer grid size. A flat profile wind of velocity $1 \mathrm{~m} / \mathrm{s}$ enters into the domain in the chosen direction. A small source of $\mathrm{NaOH}$ aerosol flowing out of SGB at the rate of $0.42 \mathrm{~m}^{3} / \mathrm{s}$ is defined on one of the sides of SGB. The top view of the domain with SGB and surrounding buildings in the Nuclear Complex is shown in Fig.3. The heights of the buildings vary from $10 \mathrm{~m}$ to $55 \mathrm{~m}$. The height of SGB is $30 \mathrm{~m}$. The code was run for unit concentration of aerosol release from source point.

Steady state solution for velocity components, pressure and concentration of the sodium aerosol are sought and k- $\varepsilon$ model with its standard closure relations is invoked to handle the turbulence. The code was run for four different wind directions and aerosol release points at three elevations viz. $10 \mathrm{~m}, 20 \mathrm{~m}$ and $30 \mathrm{~m}$ from ground.

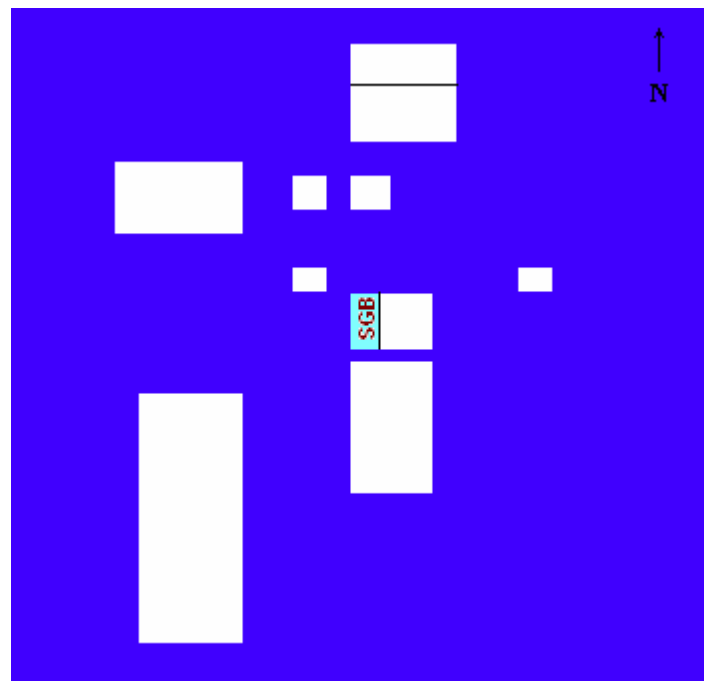

Fig.3 SGB and surrounding buildings in the Nuclear Complex

The turbulent mixing near the buildings is evident from Fig. 4 which depicts the velocity field at ground level for the wind flowing from South to North direction and the aerosol released at $30 \mathrm{~m}$ elevation.
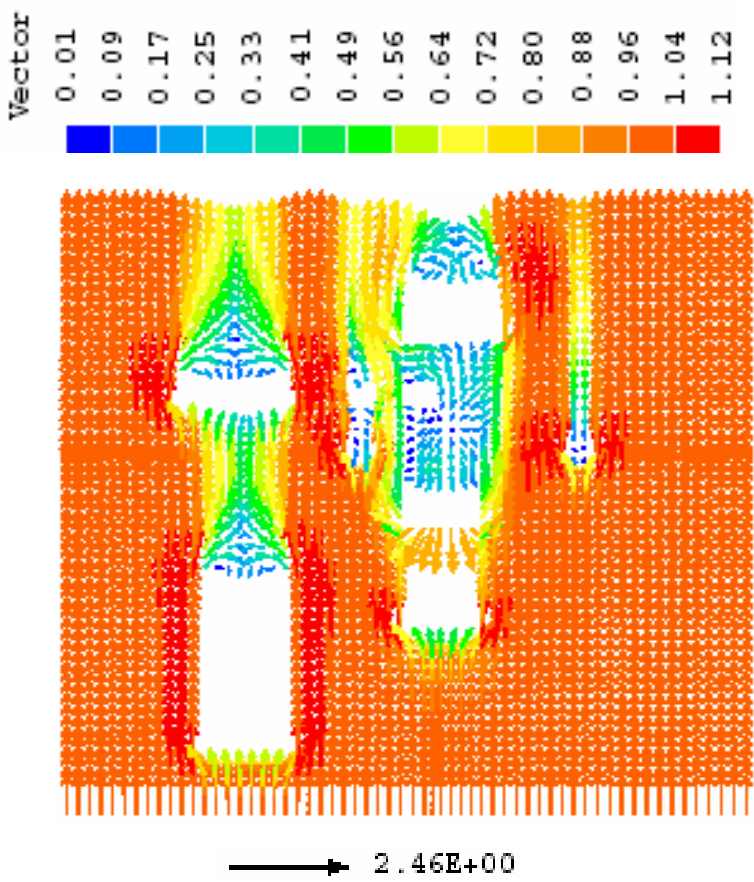

Fig.4 Velocity Vectors at Ground level 

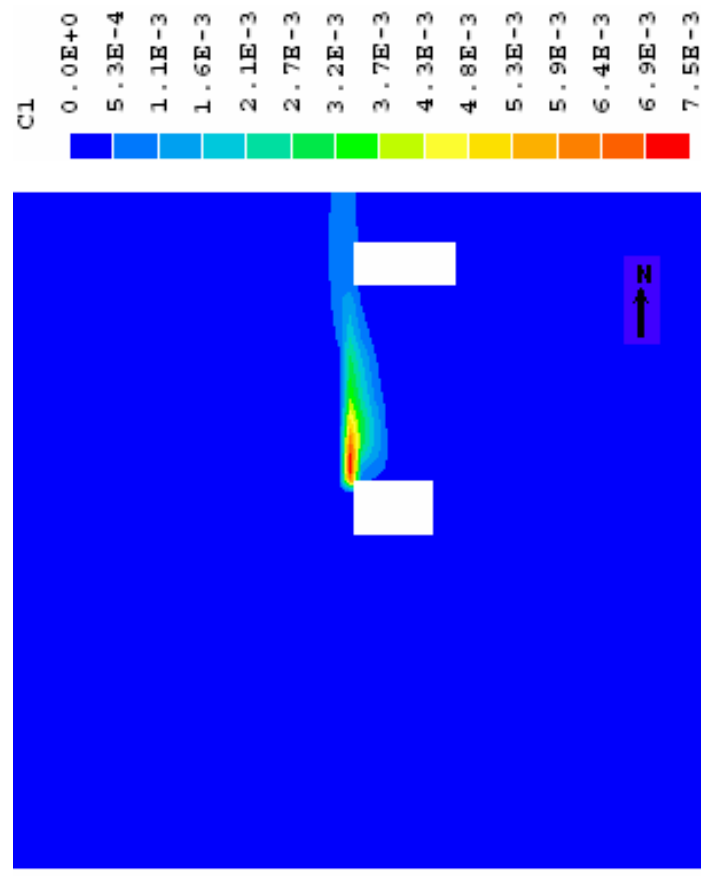

Fig.5 Concentration at source height for $S$ - $N$ wind

Fig.5 shows the aerosol concentration at the source level in the x-y plane for unit concentration of the pollutant. The dispersion is along the wind direction with the maximum concentration observed near the source exit with further dilution in the axial and radial directions.
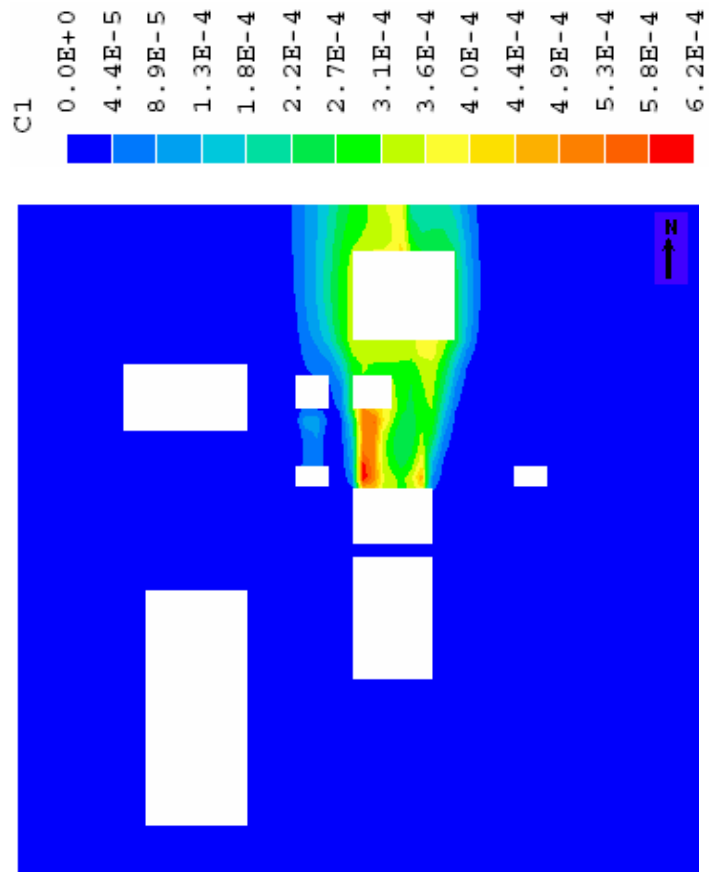

Fig. 6 Ground Level Concentration for $S-N$ Wind

Fig. 6 gives the ground level concentration contour for the same case discussed above. It is clear that the maximum concentration goes down by an order of magnitude than the concentration at source level and is confined to a small area between the SGB and the 
nearest building along the wind direction. Dispersion is also seen around other buildings located in the downwind direction. The study was also carried out for other three wind directions.

The effect of source height on the dispersion of aerosols was studied by keeping the source at $10 \mathrm{~m}, 20 \mathrm{~m}$ and $30 \mathrm{~m}$ elevations with East-West wind direction. The ground level concentrations for the first two elevations are shown below for comparison.
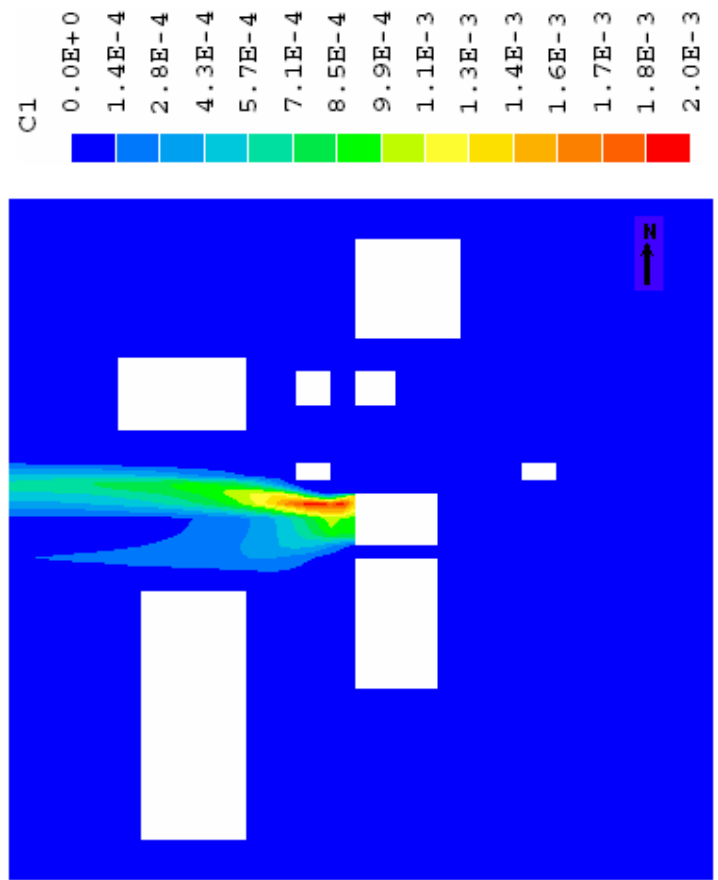

Fig.7 Ground Level Concentration for source at $10 \mathrm{~m}$
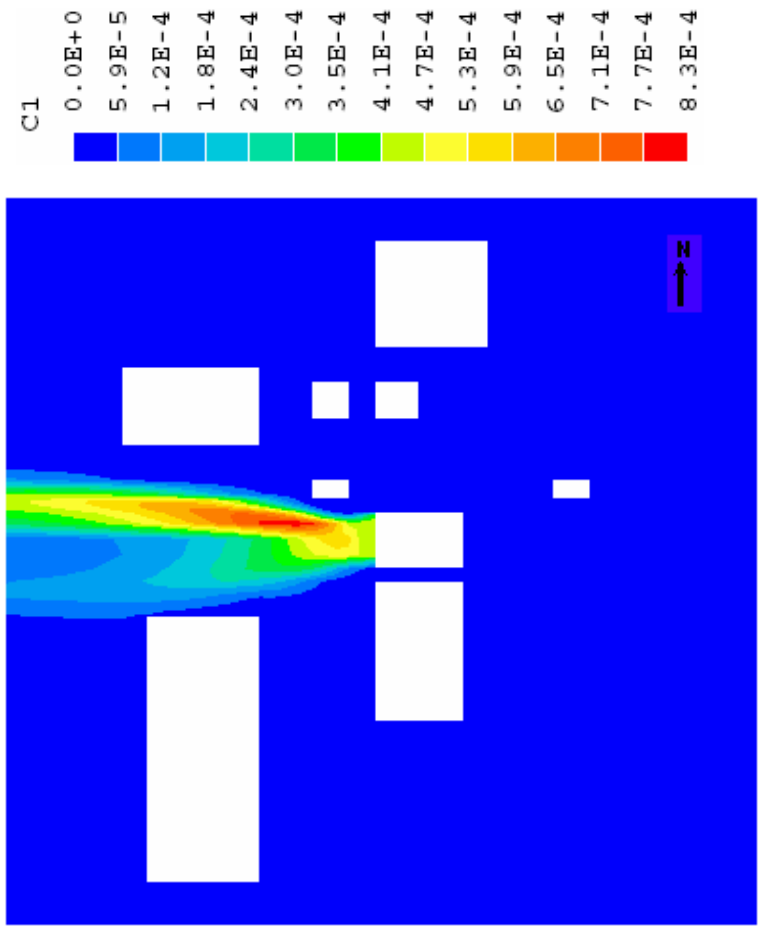

Fig.8 Ground Level Concentration for Source at $20 \mathrm{~m}$

It is seen from Fig. 7 and Fig. 8 that the maximum ground level concentration decreases with increase in source height. Also, the zone of maximum concentration at the ground level 
shifts away from the source with increase in source elevation.

\section{Conclusion}

Sodium aerosol dispersion due to sodium leak in SGB has been analysed using the Gaussian plume dispersion model for the site boundary for the open terrain and PHOENICS code for the plant boundary cases. It is found that most of the sodium hydroxide gets converted to sodium carbonate within $1 \mathrm{~km}$ from the release point. The concentration of sodium aerosols at $1600 \mathrm{~m}$ (site boundary) is of the order of $10^{-3} \mathrm{mg} / \mathrm{m}^{3}$. The PHOENICS code was run for four different wind directions. The results obtained for unit concentration of aerosols were compared. It is clear that the maximum concentration at ground level goes down by an order of magnitude than the concentration at source level, for the release height of $30 \mathrm{~m}$. Dispersion is also seen around other buildings located in the downwind direction. The study was carried out for different elevations viz. $10 \mathrm{~m}, 20 \mathrm{~m}$ and $30 \mathrm{~m}$ from ground. It is observed that higher the source height, lesser is the maximum ground level concentration. Also, the zone of maximum concentration at the ground level shifts away from the source with increase in source elevation.

In our analysis, average pool burning rate of $40 \mathrm{~kg} / \mathrm{m}^{2} \mathrm{hr}$ was taken as the input for the generation of aerosols. If the distance between the leak site and floor is long, there is a possibility of combined spray and pool fires which may result in increase in the burning rate. Hence, the effect of height of sodium leak on the rate of aerosol generation is to be studied in future.

\section{Acknowledgement}

The authors are grateful to Dr.Baldev Raj, Director, IGCAR, for providing the computing facilities. The authors also wish to express their sincere thanks to Dr.K.Velusamy, for the useful discussions and support.

\section{References}

ACGIH (American Conference of Governmental Industrial Hygienists) 1993-1994.

Venkatesan R., et al., Atmospheric Environment 36, 2933-2942, 2002.

Jalal Abedi \& Shahrouz Aliabadi, Fifth Mississippi State Conference on Differential Equations and Computational Simulations, Electronic Journal of Differential Equations, Conference 10, pp 1-11, 2003.

V.V.Shirvaikar, "Guide Book for Stack Parameters in Nuclear and Ancillary Chemical Installation”, BARC Report - 722, 1973.

W.Cherdron, S.Jordan, “Liquid Metal Engineering and Technology”, BNES, London, 1984.

Turner D.B., "Workbook of Atmospheric Dispersion Estimates”, U.S. Public Health Service Publication, 1969.

Newman R.N., Progress in Nuclear Energy, 12, No.2, 1983.

Akira YAMAGUCHI and Yuji TAJIMA, J.Nuclear Science and Technology, 40, No.10, 2003.

IAEA-TECDOC-908, "Fast Reactor Fuel Failures and Steam Generator Leaks: Transient Accident Analysis Approaches", 1996.

Holmes, NS and Morawska, L Atmospheric Environment, 40(30), pp. 5902-5928, 2006. 